ISSN: 2277-3754

ISO 9001:2008 Certified

International Journal of Engineering and Innovative Technology (IJEIT)

Volume 10, Issue 6, December 2020

\title{
Improvement Analysis of Homocysteine Biosensors based on Nanotubes with Anodized Titanium
} Dioxide

\author{
T. T. Yu Hung ${ }^{\mathrm{a}}$, W. K. Fan ${ }^{\mathrm{b}}$, J. L. Lin ${ }^{\mathrm{c}}$ \\ ${ }^{\text {a,b,c }}$ Department of Electronic Engineering, No.1, Huafan Rd., Shihting Dist., New Taipei City, Taiwan
}

Abstract: A review of the improvement of homocysteine biosensors made of nanotubes with anodized titanium dioxide was discussed here. When titanium nanotubes are used to help electron transfers in impedance tests, higher frequencies are required. Impedance analysis for titanium nanotubes vs. D-amino acid nanotubes was well-known. The absolute value impedance sensitivity $|Z|$ is $-122 \Omega / \mu M$ and the corresponding linearity coefficient is 0.990 on 104 to $105 \mathrm{~Hz}$ frequencies.

Keywords: Titania nanotubes (TNTs), biosensor; homocysteine, impedance.

\section{BACKGROUND/ OBJECTIVES AND GOALS}

Homocysteine is an important factor in thrombosis and cardiovascular disease. It is a sulfur-containing amino acid produced by the metabolism of proteins in the human body. Cyclic voltammetry is one of the most commonly used methods in electrochemical detection.

In addition, due to the high accuracy of electrochemical impedance spectroscopy, in recent years it has been widely used for the detection of minute changes, such as DNA hybridization, food safety inspection, and the detection of microorganisms $[1,2]$. Ali Taherkhani et al. used impedance method to detect homocysteine, with carbon nanotubes as electrodes and methyldopa as the mediator. The detection range is between 0.1 and $800 \mu \mathrm{M}$, and detection limit is $0.06 \mu \mathrm{M}[2]$.

Manuscript received: 26 November 2020

Manuscript received in revised form: 21 December 2020

Manuscript accepted: 09 January 2021

Manuscript Available online: 15 January 2021
Researcher detected homocysteine using impedance analysis in 2011. He used a bowl cell containing four silver electrodes, and dropped the homocysteine solution into the bowl to measure the impedance between the electrodes. When the detection frequency was between 29.65 and $212.25 \mathrm{~Hz}$, it showed good linearity ( $\mathrm{R} 2 \geqq 0.95)$ at $0-100$ $\mu \mathrm{M}$ homocysteine concentration. In Titania nanotubes, homocysteine biosensors are used as a reference electrode to immobilize the D-amino cyst acid oxidase enzyme by glutaraldehyde; they are irreversible in electrochemical research, but the device reversed when the reference electrode used was the Titania nanotube [3]. This article discusses an impedance analysis of homocysteine biosensors, including the reference electrodes of Titania nanotubes.

\section{METHODS}

Titania nanotubes were made by anodizing from high-purity (99.99\%) titanium films. The titanium nano tube anodization electrolyte composed of $0.55 \%$ ammonium fluoride, $92.08 \%$ ethylene glycol and $7.37 \% \mathrm{wt}$ high purity de-ionized water, respectively (DI water). The anodynamic process was performed in platinum as a cathode electrode and in a potential mode of $30 \mathrm{~V}$ processing during 1 hour at temperature of $30{ }^{\circ} \mathrm{C}$. The D-amino-acid oxidase enzyme and phosphate buffer fluid solution (PBS) are combined uniformly, falling into a 2-2-mm2 $\mathrm{TiO} 2$ nanotube sensing window, and glutaraldehyde is covered with homocysteine sensors after 20 minutes.. The aforementioned samples were stored for about 24 hours at $4{ }^{\circ} \mathrm{C}$ in dry conditions and were soaked in 
ISSN: 2277-3754

ISO 9001:2008 Certified

International Journal of Engineering and Innovative Technology (IJEIT)

Volume 10, Issue 6, December 2020

the PBS about 10 minutes before use. Impedance analysis used Agilent 4284A whose frequency is between $20 \mathrm{~Hz}$ and $1 \mathrm{MHz}$. The principle is to apply small amplitude sine wave voltage onto the measured electrode, and test the current value of the response. The typical impedance analysis graph is the real part of the impedance versus the imaginary part, also called the Nyquist diagram. The impedance includes the resistance of the electrolyte, the ion diffusion resistance of the solution to the surface of the electrode, and the electron transfer resistance caused by the presence of the redox species.

\section{RESULTS}

Responses to homocysteine interventions can be based on oxidation reactions and reduced in enzyme oxidation of homocysteine by producing hydrogen peroxide (H2O2). The reaction is as follow [4]:

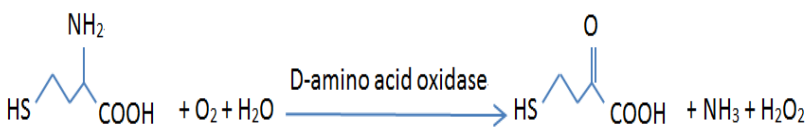

Figure 1 shows the similar-cyclic voltammetry response of homocysteine at $50 \mu \mathrm{M}$ test using the D-Amino acid Oxidase enzyme was immobilized by titanium Titania and titanium Nanotubes. The results show that the susceptibility was $53.2 \mathrm{nA} / \mu \mathrm{M}$; that the corresponding linearity of $\mathrm{R} 2$ was between $0-70 \mu \mathrm{M}$; the detection limit was about 1.5 $\mu \mathrm{M}$ [3]. It is seen in electrochemical analytics with a scanning voltage of $-2 \mathrm{~V}$ to $2 \mathrm{~V}$.In the impedance analysis, homocysteine was first measured at $10-70 \mu \mathrm{M}$ with $\mathrm{Ag} / \mathrm{AgCl}$ reference electrode and titanium dioxide nanotube A typical analysis diagram of impedance is the imaginary part versus the real part, also called the Nyquist diagram. When the concentrations of homocysteine increase, the curves of Nyquist diagram shift to the left. That is, the real impedance decreases, as shown in Figure 2(a). Take the real value of the lowest point in each concentration chart as the sensitivity and linearity; the real part sensitivity is -206 $\Omega / \mu \mathrm{M}, \mathrm{R} 2$ is 0.989 . Then take the absolute value of the impedance $|\mathrm{Z}|$ versus the frequency plot, as shown in Figure 2(b). The impedance value decreases as the concentration of homocysteine increases, showing good linearity at a frequency of $10^{4}-10^{5} \mathrm{~Hz}$, sensitivity of $-199 \Omega / \mu \mathrm{M}$ and R2 of 0.990. Figure 3(a) shows a Nyquist plot with $\mathrm{Ag} / \mathrm{AgCl}$ reference electrode vs. D-amino acid oxidase/titania nanotubes. The sensitivity of the real part is $-470 \Omega / \mu \mathrm{M}, \mathrm{R} 2$ is 0.991 , and the sensitivity is relatively increased by 264 $\Omega / \mu \mathrm{M}$. The absolute value of the impedance $|\mathrm{Z}|$ is plotted against the frequency, as shown in Fig. 3(b). It exhibits good linearity at $10^{2}-10^{3} \mathrm{~Hz}$ with a sensitivity of -468 $\Omega / \mu \mathrm{M}$ and $\mathrm{R} 2$ of 0.991 .

Figure 4(a) shows the impedance analysis of different homocysteine concentrations using both titanium dioxide nanotubes. Obviously, the arc diameter presented at higher frequencies is smaller. Electron transfer occurred at high frequency and mass diffusion occurred at low frequency. The arc diameter of electron transfer will be smaller when substrate materials are selected for higher activity. We used $\mathrm{TiO}_{2}$ nanotubes as the substrate due to the greater activity of titanium to promote the charge transfer rate faster, resulting in small overall resistance. The sensitivity of the real part is $-64.6 \Omega / \mu \mathrm{M}$ and $\mathrm{R} 2$ is 0.992 . The absolute value of the impedance $|\mathrm{Z}|$ is plotted against the frequency, as shown in Figure 4(b). The linearity is good at $10^{3}-10^{6} \mathrm{~Hz}$, the sensitivity is $-66.4 \Omega / \mu \mathrm{M}$, and $\mathrm{R} 2$ is 0.993 . The impedance analysis was performed with titania nanotubes vs. D-amino acid oxidase/titania nanotubes; the results are shown in Fig. 5(a). The sensitivity of the lowest real part is $-125 \Omega / \mu \mathrm{M}$, and $\mathrm{R} 2$ is 0.988 . The sensitivity of the embedded D-amino acid oxidase was increased by 60.4 $\Omega / \mu \mathrm{M}$. The absolute value of the impedance $|\mathrm{Z}|$ is plotted against the frequency, as shown in Figure 5(b). It exhibits good linearity at frequencies of $10^{4}-10^{5} \mathrm{~Hz}$ with a sensitivity of $-122 \Omega / \mu \mathrm{M}$ and $\mathrm{R} 2$ of 0.990 .

The use of a $\mathrm{TiO} 2$ nanotube as an electrode reference electrode will reduce the reversible device reaction barrier. The structure can be built in chips that manufacture biosensors built entirely on titanium nanotubes and 
ISSN: 2277-3754

ISO 9001:2008 Certified

International Journal of Engineering and Innovative Technology (IJEIT)

Volume 10, Issue 6, December 2020

integrated with circuits. When $\mathrm{TiO} 2$ nanotubes are used as a reference electrode, higher frequencies were needed for the promotion of electron transfer in the impedance study.

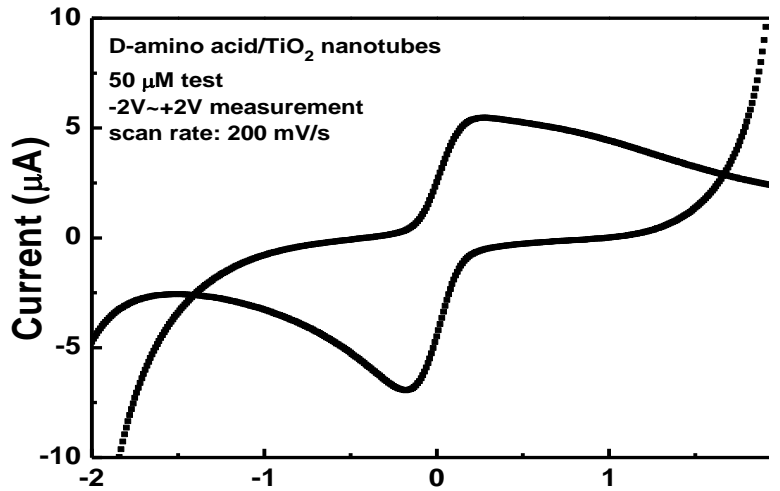

Potential vs. $\mathrm{TiO}_{2}$ nanotubes (V)

Fig. 1: Cyclic voltammetry Homocysteine measurements utilizing the immobilized D-Amino Acid Oxidase (D-Amino Acid) enzyme titanium as an electrode of reference at $50 \mu \mathrm{M}$ (HET) test

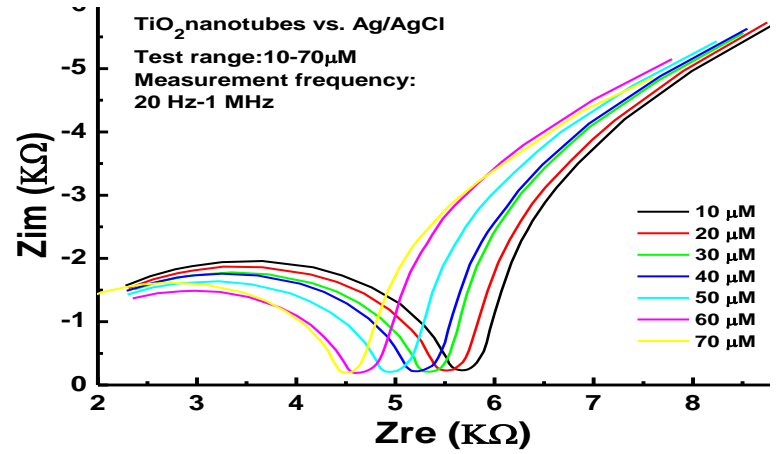

(a)

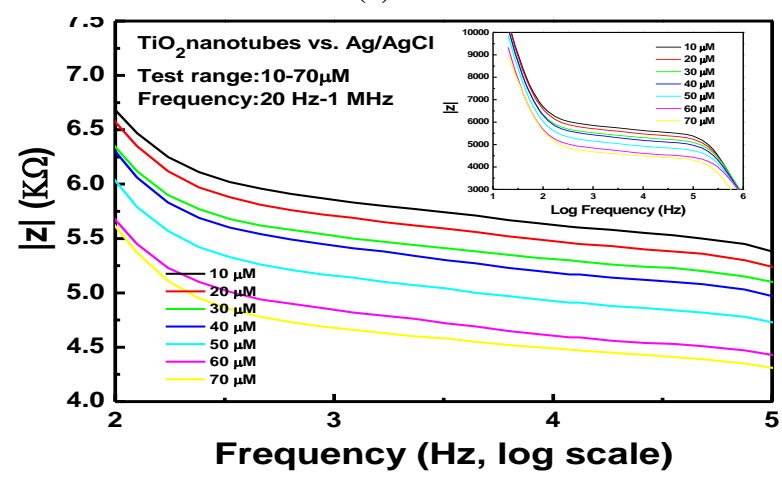

(b)

Fig. 2: Impedance analysis of (a) the imaginary part versus the real part, (b) $|\mathrm{Z}|$ versus the frequency with $\mathrm{Ag} / \mathrm{AgCl}$ reference electrode and $\mathrm{TiO} 2$ nanotube

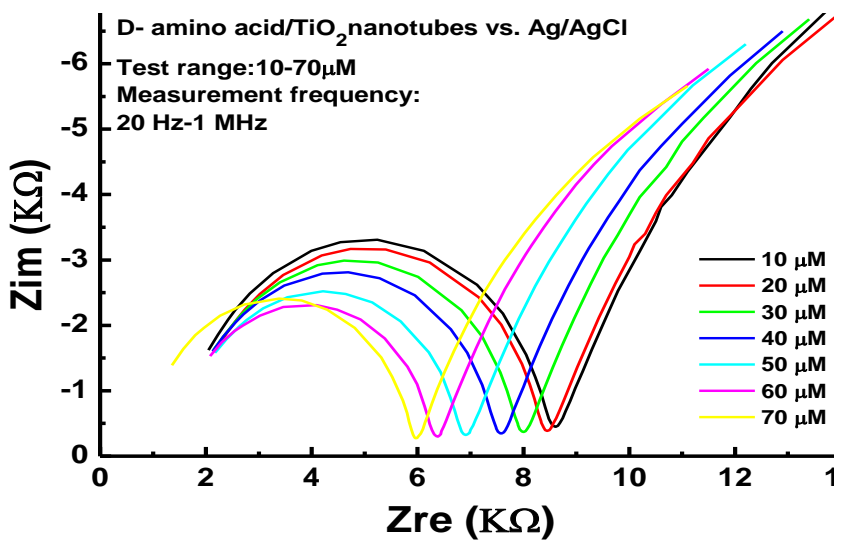

(a)

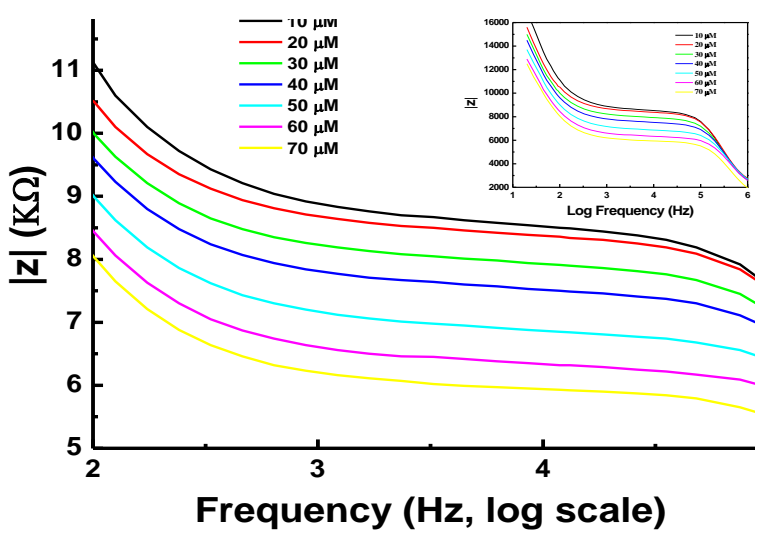

(b)

Fig. 3: Impedance analysis of (a) the imaginary part versus the real part, (b) $|\mathrm{Z}|$ versus the frequency with $\mathrm{Ag} / \mathrm{AgCl}$ reference electrode and D-amino acid oxidase/TiO2 nanotubes

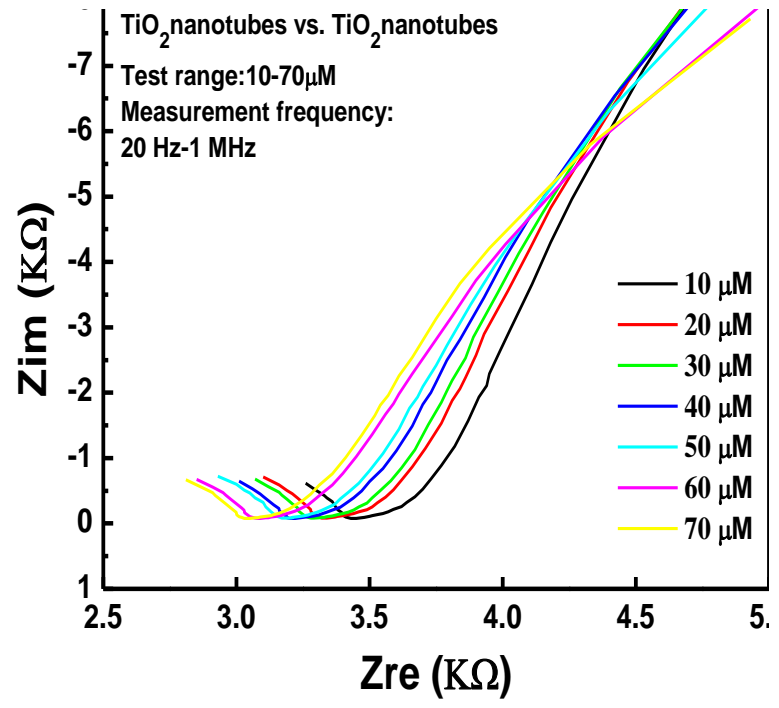

(a) 
ISSN: 2277-3754

ISO 9001:2008 Certified

International Journal of Engineering and Innovative Technology (IJEIT) Volume 10, Issue 6, December 2020

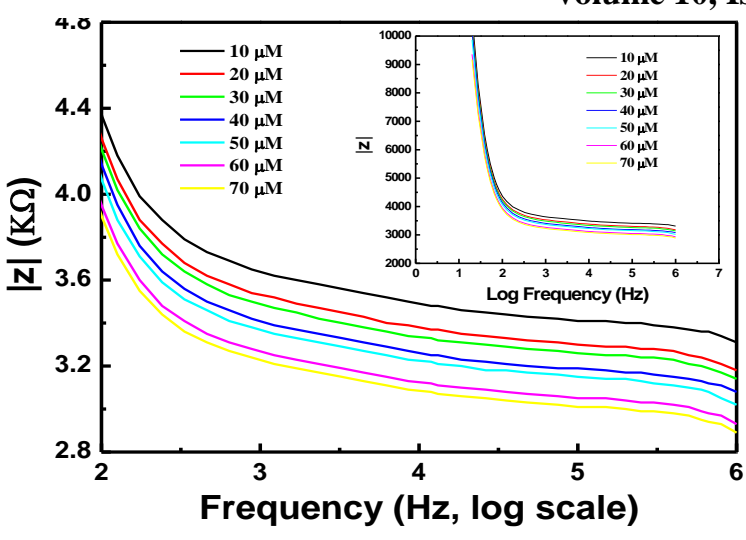

(b)

Fig. 4: Impedance analysis of (a) the imaginary part versus the real part, (b) $|\mathrm{Z}|$ versus the frequency with both $\mathrm{TiO2}$ nanotubes

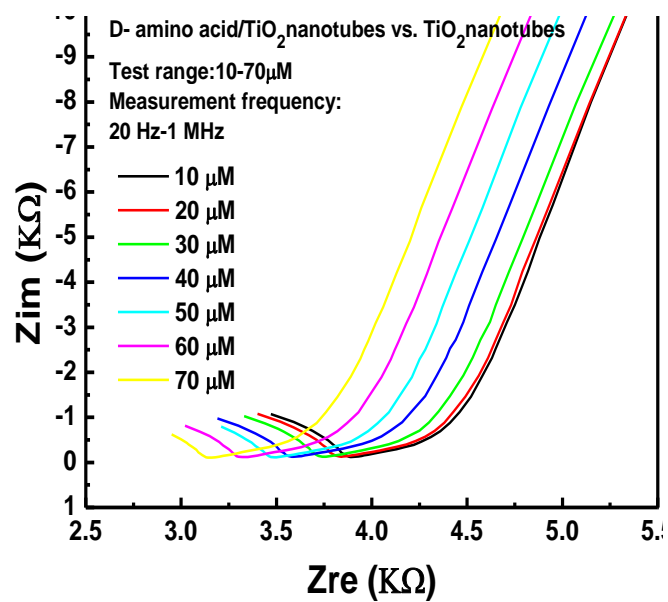

(a)

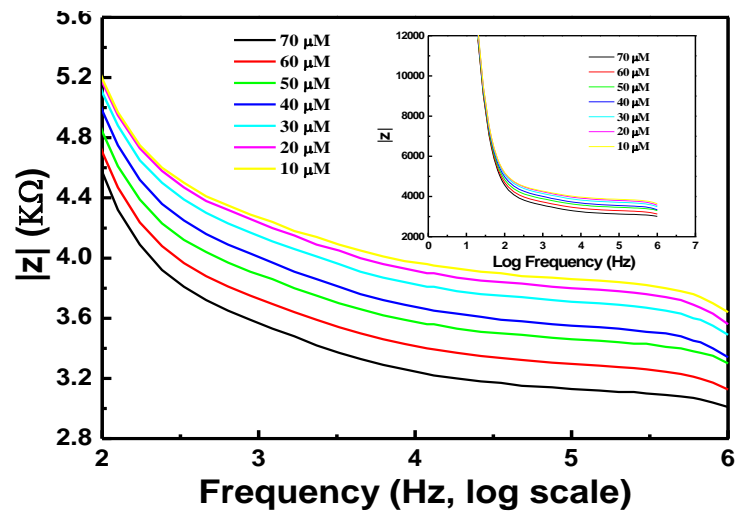

(b)

Fig. 5: Impedance analysis of (a) the imaginary part versus the real part, (b) $|\mathrm{Z}|$ versus the frequency with $\mathrm{TiO} 2$ nanotubes and D-amino acid oxidase/TiO2 nanotubes

\section{REFERENCES}

[1] Ye, J. S., Ottova, A., Tien, H. Ti., \& Sheu, F. S., "Nanostructured platinum-lipid bilayer composite as biosensor". Bio electrochemistry, Vol 59, Issue 1-2, pp: 65-72, 2003.

[2] Taherkhani, A., Bagheri, H., Karimi-Maleh, H., \& Beitollahi, H.,"Electrochemical and Catalytic Investigations of Homocysteine Using Multiwall Carbon Nanotubes Paste Electrode as a Sensor and Methyldopa as a Mediator", Journal of Basic. Appl. Sci. Res., 3(1s), pp: 57-65, 2013.

[3] Yu Hung, T. T., \& Lin, J. L.," A Study on Homocysteine Biosensors Completely Constructed on Anodized Titania Nanotubes”, IEEE Sensors Letters, 1(3), pp: 1-4, 2017.

[4] Zhang, G., Liu, D., Shuang, S., \& Choi, M. M. F.,"A homocysteine biosensor with eggshell membrane as an enzyme immobilization platform", Sensors Actuators B, vol. 114, pp: 936-942, 2006. 